\title{
Enveloping envy: reply to comments
}

\author{
Russell Belk
}

Received: 17 November 2011 / Accepted: 17 November 2011 / Published online: 30 November 2011

(C) Academy of Marketing Science 2011

All three of these comments bring up valuable additional considerations involving benign and malicious envy. Collectively, they suggest a number of promising research and theoretical perspectives and issues that enrich the ideas I have tried to present as well as offer some alternative perspectives on the nature of contemporary consumer envy. I welcome and agree with most of the comments and offer only a few additional ideas that they prompted.

Along with providing a view of envy as an emotion driven by social comparison as an antecedent and resulting in various envy-reducing actions as a consequence, Valerie Folkes suggests that even when these actions are successful in reducing the negative emotion of envy, they may have additional negative consequences such as over-indulgence. This is a point made somewhat differently by Wooten, Harrison, and Mitchell, who point out additional negative consequences of the poor striving to reduce benign envy by buying: excessive debt, overwork, and even crime. These points are well taken. Furthermore, work on materialism and consumer desire that I and others have carried out suggests that acquiring the goods we desire and thereby imitating envied others' consumption may produce unhappiness rather than happiness (Belk 1985; Belk et al. 2003). Thus, we may need to amend part of Folkes' hydraulic formula that acquiring the desired possession reduces envy and increases happiness.

I happened to be at Tilburg University when I received these comments and I shared them as well as the original paper with Niels Van de Ven. I am thankful for additional insights that came from discussing the papers with him. However, the ideas expressed here are my own.

R. Belk $(\bowtie)$

Schulich School of Business, York University,

Toronto, ON, Canada

e-mail: rbelk@schulich.yorku.ca
Folkes also usefully brings up the notion of self regulation to prevent over-indulgence. Although Folkes (see also Folkes and Matta 2007) construes self-control as a psychological variable for imposing self-restraint, it is also possible to see self-regulation as a social mechanism for inducing compliance with goals of society. This is Foucault's (1978) explanation of the shift from stateimposed discipline to self-discipline through guiltproducing self monitoring. Such self-discipline is used to elicit compliance in realms such as sexual behavior, eating, exercise, and health, each of which comes to be seen as a personal responsibility (e.g., Thompson and Hirschman 1995). This also resonates with Solomon's observation that our sumptuary constraints today may be self-imposed. However, it is also possible to see the same processes at work to keep us not only from consuming too much, but also too little. And the self-monitoring mechanism that brings this about is likely social comparison and benign envy. As Riesman (1961, p. 79) observed, "The consumer today ... is kept within limits on his consumption ... kept from splurging too much by fear of others' envy, and from consuming too little by his own envy of the others."

Solomon also brings up a number of other promising constructs and avenues of thought that should be examined with regard to benign envy-balance theory, social distance, survivor guilt, advertiser-inspired envy without a direct target, and the conditions that lead to benign versus malicious envy. But one that I find especially intriguing is to contemplate how our online "friends" encounters affect our envy. When the referent is distant or virtual the effects of advertising and anonymity in stimulating envy through comparison to the cumulative goods owned by many others, or an imagined "most" others, has an added potential to become distorted. I have tried to allude to some of 
these factors in my article, but much remains to be done concerning digital self presentation and envy.

These latter points tie into Wooten et al.'s argument that as the mediated and anonymous objects that consumers covet grow, the poor are likely to be especially impacted because this growing set of desirable objects is even further out of reach for them. Although I agree with this observation, I tried to point out that there are alternative status systems like that of cool which may be invoked as an alternative to the out-ofreach luxury consumption of more affluent consumers. In the context of clubbing, Thornton (1996) has described this practice as one of invoking subcultural capital. If the rich are portrayed owning toy poodles, eating watercress sandwiches, and playing polo, that does not necessarily mean that we covet any of these things; in fact we may elevate our own status by belittling the taste system of anyone who could aspire to own such uncool goods. This is also similar to the stereotyping that Folkes suggests.

Additional evidence of the effect of alternative status systems is found in a study by Nelissen et al. (2011). They found that adolescents with stronger status concerns accumulated more debt, except in the case of those who excelled in athletics or academics which presumably provide alternative sources of self esteem and reduce the role of envying others' possessions. Although I have argued that we are beginning to feel benign envy even toward celebrities and are beginning to be motivated to try to copy some of their apparent consumption, there are likely additional factors here as well. Lockwood and Kunda (1997) found that there was more of an attempt to emulate the consumption of admired superstars when their success seemed attainable, but when their apparent success seemed out of reach, self esteem declined instead. These findings are similar to those of Belk et al. (2003) regarding objects of consumer desire, except that we found that aspirations were reformulated in the latter case in order to provide more realizable consumption aspirations.

That the poor feel the sting of envy to a greater degree than the rich is nevertheless a reasonable and testable proposition. However, with so many goods and so many people - actual or virtual-to covet and envy, it is likely that even the most affluent can find someone to envy with either benignity or malignity. As a concluding example of the exacerbating role of the media, Kron (1975) found that the average price of the furnishings of the small single rooms depicted on the cover of March, 1975 issue of House Beautiful was $\$ 26,590$. This was at a time when the median reader family income was $\$ 15,489$. It seems doubtful that this discrepancy or its present day equivalent is likely to inspire revolution to bring down the imagined owners of these coveted cover rooms. Instead, it seems likely that readers have chosen this home magazine to provide benignly enviable consumption patterns toward which they can strive.

\section{References}

Belk, R. (1985). Materialism: trait aspects of living in the material world. Journal of Consumer Research, 12(December), 265-280.

Belk, R., Ger, G., \& Søren, A. (2003). The fire of desire: a multi-sited inquiry into consumer passion. Journal of Consumer Research, 30, 326-351.

Folkes, V., \& Matta, S. (2007). How much to use? An action-goal framework of the factors influencing consumption quantity. In N. Malhotra (Ed.), Review of marketing research, vol. 4 (pp. 33-62). Armonk: M.E. Sharpe.

Foucault, M. (1978). The history of sexuality, volume 1: An introduction. New York: Random House.

Kron, J. (1975). The house and garden blues. New Yorker, 7 (April 28), 53-56.

Lockwood, P., \& Kunda, Z. (1997). Superstars and me: predicting the impact of role models on the self. Journal of Personality and Social Psychology, 73(1), 91-103.

Nelissen, R. M. A., Van de Ven, N., \& Stapel, D. A. (2011). Status concerns and financial debts in adolescents. Social Influence, 6 (1), 39-56.

Riesman, D. (1961). The lonely crowd. New Haven: Yale University Press.

Thompson, C. J., \& Hirschman, E. C. (1995). Understanding the socialized body: a poststructuralist analysis of consumers' selfconceptions, body images, and self-care practices. Journal of Consumer Research, 22, 139-153.

Thornton, S. (1996). Club cultures: music, media and subcultural capital. Middletown: Wesleyan University Press. 